\title{
An Integrated Fuzzy Approach to Bidder Selection in Public Procurement: Serbian Government Case Study
}

\author{
Vjekoslav Bobar ${ }^{1}$, Ksenija Mandić ${ }^{2}$, Boris Delibašić ${ }^{3}$, Milija \\ Suknović ${ }^{3}$ \\ ${ }^{1}$ Administrative Agency for Common Services of Government Authorities, \\ Nemanjina 22-26, 11000 Belgrade, Serbia, vjekoslav.bobar@uzzpro.gov.rs \\ ${ }^{2}$ Crony d.o.o, Surcinski put 1M, 11070 Belgrade, Serbia, ksenija.mandic@crony.rs \\ ${ }^{3}$ University of Belgrade, Faculty of Organizational Sciences, Jove Ilica 154, 11000 \\ Belgrade, Serbia, boris.delibasic@fon.bg.ac.rs, milija.suknovic@ fon.bg.ac.rs
}

\begin{abstract}
Public procurement is one of the most significant activities within the sphere of public administration, whose primary purpose is to achieve maximized cost effectiveness and efficiency for the expenditure of public money. This principle is also known as the principle of "value for money" - meaning to achieve the best possible ratio between the amount paid and the value received. The selection of a suitable bidder within the public procurement procedure assists in our achievement of the aforementioned purpose. In this paper an integrated approach based on the fuzzy Technique for Order Preference by Similarity to Ideal Solution (fuzzy TOPSIS) method and the fuzzy Extent Analysis Method is proposed for utilization within the evaluation and bidder selection processes associated with the process of public procurement. The proposed method objectively allows for the evaluation of bidders without the setting of weights by public procurement committees and in so doing helps to avoid subjectivity in respect to the setting of weights for criteria and or sub-criteria. In order to demonstrate the effectiveness and feasibility of the proposed method and its application in public procurement, a real-life case scenario from the Government of Serbia will be presented in this paper.
\end{abstract}

Keywords: public procurement; bidder selection; fuzzy extent analysis method; fuzzy TOPSIS

\section{Introduction}

In brief, public procurement shall mean the procurement of goods, services or works, in the manner and under the conditions as prescribed by the Public Procurement Law [1]. As active participants in this process, there appear two categories of actors, these being: the contracting authorities as procurers and the 
economic operators as the bidders. The contracting authority is the government authority or institution from within the public administration sphere. The bidder shall imply a person engaged in the procurement procedure who offers to deliver goods, provide services and or perform works [1]. Public procurement is very important for both the citizens and the economy of any country, and this is no different in the Republic of Serbia. The primary purpose of this process is to achieve cost effectiveness and thereby attain an implicit level of efficiency as regards the expenditure of public money. This principle is also known as the principle of "value for money" - meaning to achieve the best possible ratio between the amount paid and the value received. The importance of this process becomes evident when we consider the fact that in Serbia public procurement accounts for some $10 \%$ of gross domestic product (GDP), that in the EU it approximates to $19 \%$ of GDP [2] and that globally, public procurement represents around $15 \%$ of the world's GDP [3]. The specific characteristic of public procurement is that this process must comply with specific legislative requirements. For example, in the EU this matter is regulated by the 2004/18/EC Directive, also called the Public Procurement Directive [4, 5]. In Serbia, although it is not yet an EU member state, existing EU regulations within the public procurement sphere are transferred into Serbian legislation through the application of Public Procurement Law [1]. In either case, the law's documents establish the need for the application of one of the two following criteria when evaluating potential bids: the Lowest Price offered and the Most Economically Advantageous Tender (MEAT) $[1,4,5,6]$. In this paper, we will consider the MEAT criterion which is itself based on various elements of those criteria associated with the concept of public procurement. The MEAT criterion usually considers non-price factors together with prices in the evaluation of potential bids [7], the evaluation factors and weights assigned to the criteria or sub-criteria should be publicly announced in advance of the tender [7] and every bid receives a numerical score for each non-price evaluation factor [7]. As opposed to the private sector, in the public sector, we have the awarding committee for public procurement (usually a group of experts selected by a public authority) $[4,6]$. This committee consists of a number of decision makers who must adhere to established public procurement principles: Principle of Efficiency and Cost-Effectiveness, Principle of Ensuring Competition, Principle of Transparency in Public Procurement Procedure, Principle of Equality of Bidders and Principle of Environmental Protection and Ensuring [1]. Considering these principles, a public procurement committee needs to treat all potential bidders equally and their selection must be founded on a rigorous ranking system, obtained through the application of transparent decision procedures [4]. For this reason, the method of awarding should have the largest possible degree of objectivity [4]. Therefore, a group decision making process for an alternative selection in public procurement is very useful [8]. Essentially, the process of selecting a bidder within the public procurement can be reduced to the multi-criteria decision making (MCDM) approach [9] which requires that the selection be made from amongst the decision alternatives (potential bidders) in 
accordance an evaluation of their inherent attributes (quantitative and qualitative) [10]. In many cases qualitative criteria can be described using linguistic variables. For example, if we have quality as a qualitative criterion, we can define this criteria as bad, good, satisfied, excellent, etc. These variables are able to handle imprecision and also offer us the basis for natural language computation [11]. The linguistic variables are uncertain and in order to make a comparison between the qualitative and quantitative criteria, we can use the Fuzzy Sets Theory. The fuzzy approach performs numerical computation by using linguistic labels stimulated by membership functions [12]. The Fuzzy Sets Theory was introduced by Zadeh [13] as a powerful tool in order to effectively deal with ambiguities, vagueness and uncertainties when dealing with special complexities and or deficiencies in information as concerns the opinions of experts [14]. The major contribution of this theory is its ability to represent vague data; it also allows for mathematical operations and programming to be applied to the fuzzy domain $[10,15,16,17]$.

At this point, we should emphasize that one of the authors of this paper, as a member of public procurement committees, was involved in the realization of more than a hundred public procurements within the Serbian government over the course of the past ten years. During this period a problem was identified in that there exists a high level of subjectivity as concerns the determination of the respective weights assigned to each individual criteria on the part of the public procurement committee. In some instances the weights assigned to certain criteria have a tendency to favor one bidder over another, thus violating the aforementioned public procurement principles. In order to avoid such a scenario, in this paper we propose an approach based on the integration of the fuzzy Extent Analysis Method and the fuzzy TOPSIS method. This integrated model is very objective and allows for the evaluation of bidders without the setting of weights on the part of a potentially subjective public procurement committee. Using this model and taking into consideration the preferences of the public procurement committee, we can determine the respective weights of criteria and sub-criteria in accordance with a process of mathematical calculation.

\section{The Public Procurement as MCDM Phenomenon}

As we have already stated the process of public procurement implies the sourcing of goods, services and or work by the government authority, in that manner and under those conditions as prescribed by the Public Procurement Law [1]. This process consists of two main stages: the pre-award stage and the post-award stage. The pre-award stage has the sub-stages like call preparation for public procurement, notification, bid submission, bid evaluation and the selecting the most suitable bid. The post-award stage has sub-stages like ordering, invoicing and payment [18]. The bid evaluation and subsequent selection of the most 
acceptable bid in the public procurement procedure can be viewed from the perspective of the MCDM phenomenon [9], where a contracting authority must compare the bids against pre-defined criteria, select one of the potential bids or conversely reject all of them. In order to define the bidder selection problem in the public procurement, we need to make introduction a set of bidders $B=\left\{b_{1}, b_{2}, \ldots, b_{m}\right\}$ and a set of conflicting criteria $C=\left\{c_{1}, c_{2}, \ldots, c_{n}\right\}$. Moreover, the different bidders and their bids have to be ranked, taking into account several parameters connected to the bidder's characteristics as also those of the product/service/work features [19]. Accordingly, we associate to each bidder $b_{i} \in B$ the following n-tuple: $d_{i 1}, d_{i 2}, \ldots, d_{i n}$ where $d_{i j}$ represents the value of the performance index characterizing the $i^{\text {th }}$ bidder with $i=1, \ldots, m$ with respect to the $j^{\text {th }}$ criterion with $j=1, \ldots, n$ [19]. In addition, the input data are collected in an $m x n$ decision matrix $D M$, where $m$ is the number of available bidders and $n$ is the number of criteria on the grounds of which the ranking of bidders is performed [19]. Hence, the generic element $d_{i j}$ of a $D M$, with $i=1, \ldots, m$ and $j=1, \ldots, n$, represents the $j^{\text {th }}$ performance value the $i^{\text {th }}$ alternative bidder $b_{i}$ [19]. The input data are completed by the criteria importance, i.e., each criterion $c_{j}$ with $j=1, \ldots, n$ is associated to a weight $w_{j}$, with $\sum_{j=1}^{n} w_{j}=1[19]$. When the contract is awarded in accordance with the already mentioned MEAT criterion, quantitative and qualitative factors are simultaneously considered [4]. The mentioned EU Directive 2004/18/EC imposes the use of the Linear Weighting technique (when possible) in public tenders to be awarded according to the MEAT criterion [6]. Usage of this technique has its inherent limitations because, when MEAT is used, the public procurement committee can favor a specific bidder by assigning a high weight to a criterion which only that bidder can to fully satisfy [6]. Consequently, this method is oftentimes characterized by subjective choices which have a tendency of enabling corrupt behavior [6]. In the process of applying the Linear Weighting technique in public procurement, the contracting authority needs to fix and publish the importance of the respective weights assigned in advance, before the notification of the public procurement call. In addition, when this awarding arrangement is used, the contracting authority can grant an unfair advantage to a given bidder by assigning a high weight to a criterion that only this competitor can meet fully $[4,6,20]$. In practice, the application of a methodology for the allocation of specific weights to individual criteria is such that it has a tendency to be lacking in objectivity. Moreover, when the weights are subjectively determined, it is still possible to create an unfair evaluation procedure in which too much emphasis is placed on particular evaluation factors, thus favoring, intentionally or otherwise those bidders that score high in the corresponding factors [7]. 
In order to avoid the aforementioned limitations, this paper will go on to present an integrated fuzzy approach to bidder selection within the public procurement. We will give an example of the application of the fuzzy TOPSIS methodology integrated with the fuzzy Extent Analysis Method in the public procurement process of a Data Storage Hardware System from Serbian government. In this public procurement process, we used the fuzzy Extent Analysis Method to mathematically calculate the weights of each criteria and sub-criteria. In so doing, we excluded the possibility of the subjective assigning of weight to each criterion and sub-criterion which was not the case with the aforementioned Linear Weighting technique which is recognized by the Public Procurement Law both in the EU and Serbia. The obtained weights are used to determine the ranking of the final bid through the application of the fuzzy TOPSIS methodology.

\section{The Fuzzy Extent Analysis Method}

Chang proposed the fuzzy Extent Analysis Method, which we use in this paper [21]. This method consists of several steps the first of which is the determination of the value of fuzzy synthetic extent with respect to the $i^{\text {th }}$ object. This value can be expressed by Eq. (1): $S_{i}=\sum_{j=1}^{n} M_{g_{i}}^{j} \otimes\left[\sum_{i=1}^{n} \sum_{j=1}^{m} M_{g_{i}}^{j}\right]^{-1}$

In Eq. (1), values $M_{g_{i}}^{1}, M_{g_{i}}^{2}, \ldots, M_{g_{i}}^{m}, i=1,2, . . n$, represent triangular fuzzy numbers (TFN).Value $g_{i}$ is an element from sets of goals $G=\left\{g_{1}, g_{2}, \ldots, g_{m}\right\}$. A TFN is denoted simply as $(l / m, m / u)$ or $(l, m, u)$. The parameters $l, m$ and $u(l \leq$ $m \leq u$ ), respectively, denote the smallest possible value, the most promising value, and the largest possible value that describes a fuzzy event $[10,15,16]$. While there are various operations on TFNs, only the important operations used in this paper are illustrated (addition and multiplication) [15, 16]. If we define two positive TFNs, $\left(l_{1}, m_{1}, u_{1}\right)$ and $\left(l_{2}, m_{2}, u_{2}\right)$, then the operation of addition we can define as $\left(l_{1}, m_{1}, u_{1}\right)+\left(l_{2}, m_{2}, u_{2}\right)=\left(l_{1}+l_{2}, m_{1}+m_{2}, u_{1}+u_{2}\right)$. Also, the operation of multiplication we can define as $\left(l_{1}, m_{1}, u_{1}\right) *\left(l_{2}, m_{2}, u_{2}\right)=$ $\left(l_{1} * l_{2}, m_{1} * m_{2}, u_{1} * u_{2}\right)[15,16]$. In order to get $\sum_{j=1}^{n} M_{g_{i}}^{j}$ from Eq. (1), we need to perform the operation of fuzzy addition to $m$ extent analysis [22, 23, 24, 25] numbers in the matrix as $\sum_{j=1}^{n} M_{g_{i}}^{j}=\left(\sum_{j=1}^{m} l_{j}, \sum_{j=1}^{m} m_{j}, \sum_{j=1}^{m} u_{j}\right)$. In order to get 
expression $\left[\sum_{i=1}^{n} \sum_{j=1}^{m} M_{g_{i}}^{j}\right]^{-1}$ from Eq. (1), we need to compute the expression $\sum_{i=1}^{n} \sum_{j=1}^{m} M_{g_{i}}^{j}$ as $\sum_{i=1}^{n} \sum_{j=1}^{m} M_{g_{i}}^{j}=\left(\sum_{i=1}^{n} l_{i}, \sum_{i=1}^{n} m_{i}, \sum_{i=1}^{n} u_{i}\right)$ and then, we need to take inverse values as $\left[\sum_{i=1}^{n} \sum_{j=1}^{m} M_{g_{i}}^{j}\right]^{-1}=\left(\frac{1}{\sum_{i=1}^{n} u_{i}}, \frac{1}{\sum_{i=1}^{n} m_{i}}, \frac{1}{\sum_{i=1}^{n} l_{i}}\right)$. The next step is computation the degree of probability of triangular fuzzy numbers $M_{2}=\left(l_{2}, m_{2}, u_{2}\right)$ and $M_{1}=\left(l_{1}, m_{1}, u_{1}\right)$ as Eq. (2):

$$
V\left(M_{2} \geq M_{1}\right)=\operatorname{hgt}\left(M_{1} \cap M_{2}\right)=\left\{\begin{array}{ccc}
1, & \text { if } & m_{2} \geq m_{1} \\
0, & \text { if } & l_{1} \geq l_{2} \\
\frac{l_{1}-u_{2}}{\left(m_{2}-l_{2}\right)-\left(m_{1}-l_{1}\right)} & & \text { otherwise }
\end{array}\right.
$$

For comparison of two triangular fuzzy numbers $M_{1}$ and $M_{2}$, we must take both the values of $V\left(M_{1} \geq M_{2}\right)$ and $V\left(M_{2} \geq M_{1}\right)[22,25,26,27]$. The next step is computation the degree of probability for a convex fuzzy number as $V\left(M \geq M_{1}, M_{2}, \ldots, M_{k}\right)=\min V\left(M \geq M_{i}\right), i=1,2, . ., k$. If we suppose that $d^{\prime}\left(A_{i}\right)=\min V\left(S_{i} \geq S_{k}\right), k \neq i, k=1,2, . ., n$, then the weight vector is computed as $W^{\prime}=\left(d^{\prime}\left(A_{1}\right), d^{\prime}\left(A_{2}\right), \ldots, d^{\prime}\left(A_{n}\right)\right)^{T}$

where $A_{i}, \mathrm{i}=1,2, \ldots, \mathrm{n}$ represents a matrix with $n$ elements $[22,25,26,27,28]$. At the end, on a process of normalization, we get the normalized weight vectors as $W=\left(d\left(A_{1}\right), d\left(A_{2}\right), \ldots, d\left(A_{n}\right)\right)^{T}$ a fuzzy number $W$ is not a fuzzy number [22, $25,26,27,28]$.

\section{The Fuzzy TOPSIS Method}

The fuzzy TOPSIS method represents an extension of the classical TOPSIS method. The classical TOPSIS method proposed by [29] seeks to illustrate the ranking of a set of alternatives through their distances from the most optimistic (positive ideal solution) to the most pessimistic (negative ideal solution) points. The reason for the fuzzy extension of the classical TOPSIS method lies in the fact 
that the classical TOPSIS method uses precise and crisp values for the weights of criteria and the ratings of alternatives. However, in the public procurement, we use non-crisp values for criteria in solving bidder selection problem. These non-crisp values can be expressed as linguistic variables. For this reason, the fuzzy TOPSIS method is proposed where the weights of criteria and ratings of alternatives are evaluated by linguistic variables represented by fuzzy numbers to deal with the deficiency in the classical TOPSIS [24, 27, 30, 31]. The fuzzy TOPSIS method consists of several steps the first of which is the formation of a committee of decision makers. In this committee that has $K$ decision makers, fuzzy rating of each decision maker $D_{k}, k=1,2, . ., K$ can be represented as triangular fuzzy number $\tilde{R}_{k}, k=1,2, \ldots, K$ with membership function $\mu_{\tilde{R}_{k}}(x)[24,27,30,32,33]$. The next step includes determination of evaluation criteria, selection of appropriate linguistic variables for evaluating criteria and alternatives and aggregation of the weights of evaluation criteria.

If the fuzzy number ratings of all decision makers are described as triangular fuzzy numbers $\tilde{R}_{k}\left(a_{k}, b_{k}, c_{k}\right), k=1,2, \ldots, K[24,27]$, then the aggregated fuzzy rating can be determined as $\breve{R}=(a, b, c), \quad k=1,2, \ldots, K$ using expressions $a=\min _{k}\left\{a_{k}\right\}, b=\frac{1}{K} \sum_{k=1}^{K} b_{k}, c=\max _{k}\left\{c_{k}\right\}[24,27]$. If the fuzzy rating and importance weight of the $k^{\text {th }}$ decision maker are $\tilde{x}_{i j}\left(a_{i j k}, b_{i j k}, c_{i j k}\right)$ and $\widetilde{w}_{i j k}\left(w_{j k 1}, w_{j k 2}, w_{j k 3}\right), i=1,2, \ldots, m ; j=1,2, \ldots, n$, respectively [24, 27, 30, 32, 33], then the aggregated fuzzy ratings $\left(\tilde{x}_{i j}\right)$ of alternatives with respect to each criterion can be found as $\left(\tilde{x}_{i j}\right)=\left(a_{i j}, b_{i j}, c_{i j}\right),[24,27,30,32,33]$ which is represented as $a_{i j}=\min _{k}\left\{a_{i j k}\right\}, b_{i j}=\frac{1}{K} \sum_{k=1}^{K} b_{i j k}, c_{i j}=\max _{k}\left\{c_{i j k}\right\}$. In the next step, for each criterion we calculate the aggregated fuzzy weights $\left(\tilde{w}_{i j}\right)$ as $\left(\tilde{w}_{j}\right)=\left(w_{j 1}, w_{j 2}, w_{j 3}\right)$

where $w_{j 1}=\min _{k}\left\{w_{j k 1}\right\}, w_{j 2}=\min _{k}\left\{w_{j k 2}\right\}, w_{j 3}=\min _{k}\left\{w_{j k 3}\right\}$.After this, we create the fuzzy decision matrix as $\breve{D}=\left\lfloor\breve{x}_{i j}\right\rfloor_{m x n}, i=1,2, \ldots, m ; j=1,2, \ldots, n$, [33] and calculate the criteria as $\breve{W}=\left[\breve{w}_{1}, \breve{w}_{2}, \ldots, \breve{w}_{n}\right]$ where $\left(\tilde{x}_{i j}\right)=\left(a_{i j}, b_{i j}, c_{i j}\right)$ and $\left(\tilde{w}_{j}\right)=\left(w_{j 1}, w_{j 2}, w_{j 3}\right), i=1,2, \ldots, m ; j=1,2, \ldots, n$, can be approximated by positive triangular fuzzy numbers [24, 27, 33]. After constructing the fuzzy decision matrix, the normalization of fuzzy decision matrix 
is accomplished using linear scale transformation [24, 26, 27]. The calculation is made as $\breve{r}_{i j}=\left(\frac{a_{i j}}{c_{j}^{*}}, \frac{b_{i j}}{c_{j}^{*}}, \frac{c_{i j}}{c_{j}^{*}}\right), c_{j}^{*}=\max _{i} c_{i j}$. The normalized fuzzy matrix can be represented as $[24,26,32,33] \breve{R}=\left[\tilde{r}_{i j}\right]_{m x n}, i=1,2, \ldots, m ; j=1,2, \ldots, n$, where $\tilde{r}_{i j}$ are the normalized values of $\left(\tilde{x}_{i j}\right)=\left(a_{i j}, b_{i j}, c_{i j}\right)[26,32]$. In the next step, we create the weighted, normalized fuzzy-decision matrix as

$\breve{V}=\left[\breve{v}_{i j}\right]_{m x n}, i=1,2, \ldots, m ; j=1,2, \ldots, n$

where $\breve{v}_{i j}=\breve{r}_{i j}(\bullet) \breve{w}_{j},\left(\breve{w}_{j}\right.$ represents the importance weight of the criterion $\left.C_{j}[24,27]\right)$. According to the weighted, normalized fuzzy decision matrix, a normalized positive triangular fuzzy numbers can also approximate the elements $\breve{v}_{i j}, \forall i, j[24,27,30,33]$. The computation of fuzzy positive-ideal solution $\left(F P I S, A^{*}\right)$ and the fuzzy negative-ideal solution $\left(F N I S, A^{-}\right)$represents next step. These solutions can be expressed as

$$
\begin{aligned}
& A^{*}=\left\{\breve{v}_{1}^{*}, \breve{v}_{2}^{*}, \ldots, \breve{v}_{i}^{*}\right\}=\left\{\max _{i} v_{i j} \mid(i=1,2, . . m ; j=1,2, . ., n)\right\} \\
& A^{-}=\left\{\breve{v}_{1}^{-}, \breve{v}_{2}^{-}, \ldots, \breve{v}_{i}^{-}\right\}=\left\{\min _{i} v_{i j} \mid(i=1,2, . . m ; j=1,2, . ., n)\right\}
\end{aligned}
$$

Based on the weighted, normalized fuzzy decision matrix, the ranges belong to the closed interval $[0,1][26,32]$. Therefore, the FPIS and FNIS can be defined as $(1,1,1)$ and $(0,0,0)$, respectively [18]. After computation of FPIS and FNIS, we make the computation of the distance of each alternative from FPIS and FNIS as follows [24, 25, 30, 32, 33]:

$$
\begin{aligned}
& D_{i}^{*}=\sum_{j=1}^{n} d\left(\tilde{v}_{i j}, \tilde{v}_{j}^{*}\right), i=1,2, . ., m \\
& D_{i}^{-}=\sum_{j=1}^{n} d\left(\tilde{v}_{i j}, \tilde{v}_{j}^{-}\right), i=1,2, . ., m
\end{aligned}
$$

The distance measurement between two fuzzy numbers [27,33] $\tilde{a}=\left(a_{1}, a_{2}, a_{3}\right)$ and $\tilde{b}=\left(b_{1}, b_{2}, b_{3}\right)$ can be calculated by the Vertex method as $d(\tilde{a}, \tilde{b})=\sqrt{\frac{1}{3}\left[\left(a_{1}-b_{1}\right)^{2}+\left(a_{2}-b_{2}\right)^{2}+\left(a_{3}-b_{3}\right)^{2}\right]}[24,26,27]$. 
In the penultimate step, we make computation of similarities to ideal solution using Eq. (10) [24, 30, 33]:

$$
C C_{i}=\frac{D_{i}^{-}}{D_{i}^{*}+D_{i}^{-}}, i=1,2, . ., m
$$

where $C C_{i}$ range belongs to the closed interval [0,1] [32]. Finally, the last step includes ranking alternative with maximum $C C_{i}$ or rank alternative according to $C C_{i}$ in descending order [23, 26, 33, 34].

\section{The Proposed Model of Bidder Selection in Public Procurement}

In this paper, we propose the model for bidder selection in the public procurement process which is a hybrid composed of the fuzzy Extent Analysis Method and the fuzzy TOPSIS method. The proposed model consists of three basic steps (see Figure 1):

Step 1: Identification of criteria and bidders and constructing the problem into a hierarchy.

Step 2: Calculation of criteria and bidders with the fuzzy Extent Analysis Method computations.

Step 3: Evaluation of bidders using the fuzzy TOPSIS and final ranking of bidders, according to fuzzy TOPSIS obtained results.

In the first step, after the notification and submission phases have been completed, the bidders, criteria which is to be used in the subsequent evaluation process are determined. After this, we create the decision hierarchy tree which is then approved by public procurement committee. Thereafter follows the second step where weights are assigned to the criteria through the implementation of the fuzzy Extent Analysis Method. In this step, we create fuzzy matrixes of comparison, in order to determine the weights of criteria. The values of the elements of the fuzzy matrixes of comparison can be determined using the public procurement committee's preferences which are based on the scale from Table 1. Then the fuzzy matrixes of comparison for decision criteria and its priority vectors are determined. This is followed by the calculation of the priority vectors for the decision hierarchy and the calculated weight of the criteria are approved by the public procurement committee. At the end of the whole process of calculation, in the last step, the final ranking of the bidders is determined according to $C C_{i}$ calculated by fuzzy TOPSIS in descending order. 


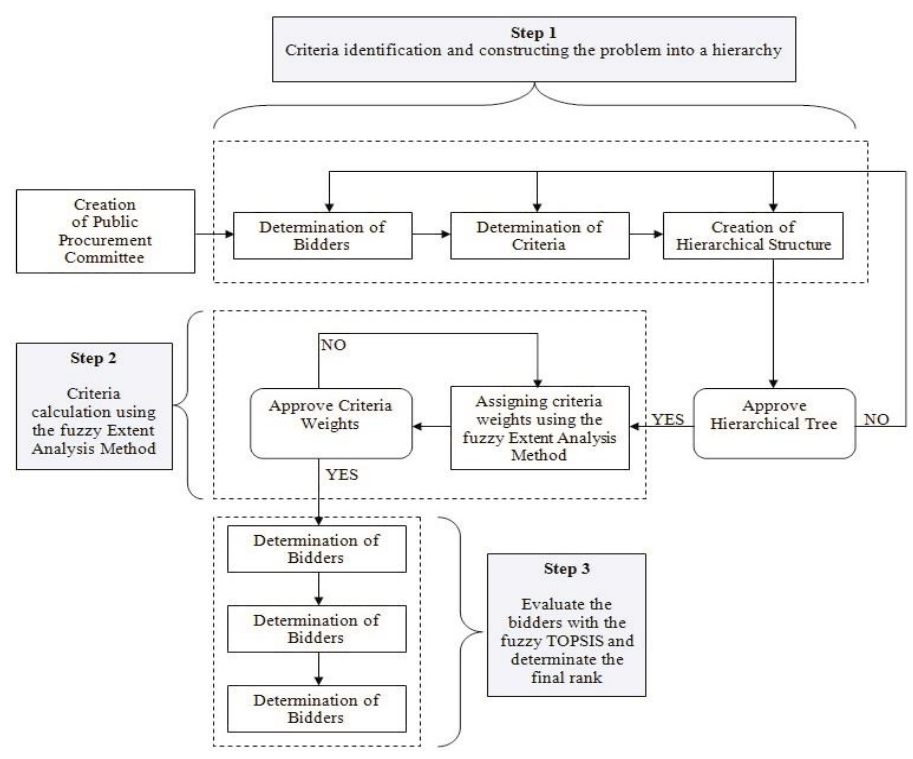

Figure 1

The proposed model of bidder selection in public procurement

In the next sections, we will give a practical application of the described model through a public procurement case study from within a Serbian government organization called the Administrative Agency for Common Services of Government Authorities. This organization has published a call for tender for a Data Storage Hardware System which represents a complex system for the recording (storing) of information (usually Big Data). After the public opening of the bids, the public procurement committee selected three bidders $\left(B_{A}, B_{B}, B_{C}\right)$ who met the legal requirements for participation in public procurement.

\subsection{Identification of Criteria and Bidders and Constructing the Problem into a Hierarchy}

The starting point for the identification of the main criteria for bidder selection was the list of criteria from [1]: Offered price, Current costs, Quality, Technical advantages, Warranty period, Time of delivery, Obligations concerning spare parts, etc. From amongst these criteria, the members of the public procurement committee were asked to identify the most relevant or to propose other criteria without any restriction in the number to be selected. After a round of meetings, the members of the public procurement committee agreed upon the four main criteria and nineteen sub-criteria were linked to the subject matter of the public procurement of a Data Storage Hardware System. The main criteria were as follows: Technical Features (TF) with sub-criteria Technical Performance (TP), 
Quantities Needed (QU), Time of delivery (TD), Warranty Period (WP), Quality of Packaging (QP) and Quality Certificate (QC); Bidder Profile (BP) with subcriteria Solvency (SO), Market Position (MP), References (RE) and Professional Relations (PR); Financial Aspect (FA) with sub-criteria Offered Price (OP), Transport Costs (TC), Customs Fees (CF) and Payment Conditions (PC) and Support and Services (SS) with sub-criteria Service (SE), Training Aids (TA), Technical Support (TS), Post-warranty Maintenance (MA) and Obligations concerning spare parts (SP). The hierarchy of the selection criteria and decision alternatives (i.e., bidders) can be seen in Figure 2.

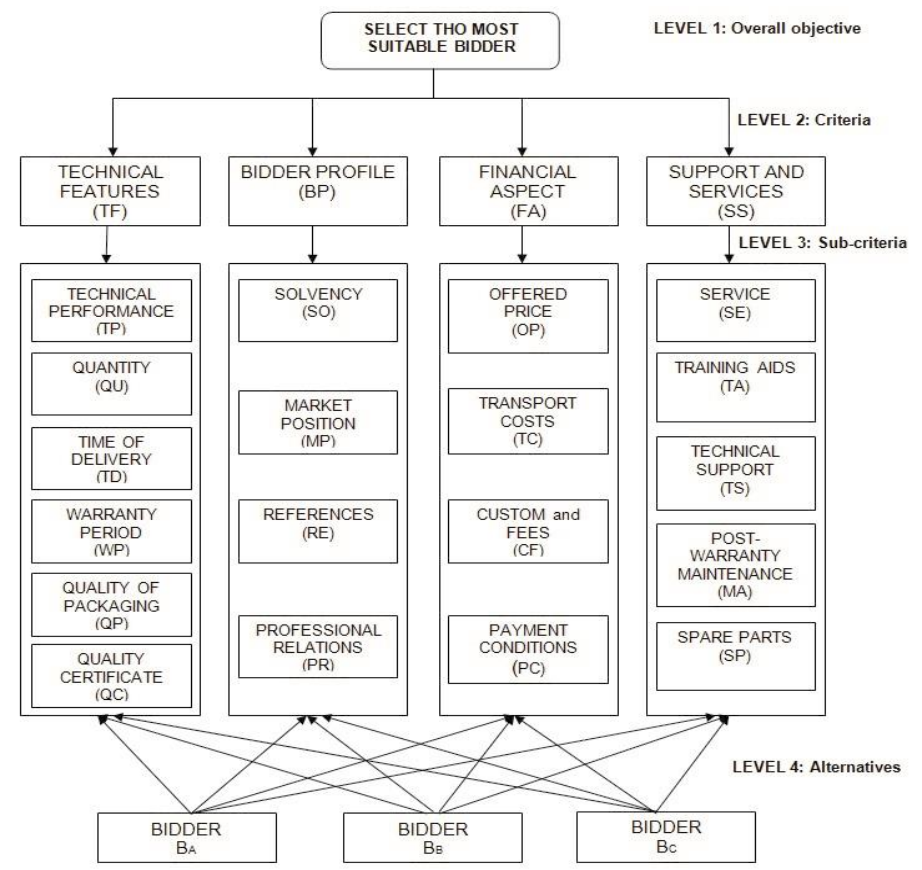

Figure 2

The hierarchy tree

\subsection{Calculation of Criteria and Bidders using the Fuzzy Extent Analysis Method}

Comparison of criteria, sub-criteria and bidders is facilitated for the experts by means of a Linguistic Importance Scale (see Table 1) [35] and the priority weights are calculated using the fuzzy Extent Analysis method.

The priority weights calculations for essential criteria and sub-criteria are given in Tables 2, 3, 4 and 5 . 
Table 1

Linguistic scale of importance

\begin{tabular}{|c|c|c|}
\hline $\begin{array}{c}\text { Linguistic scale of } \\
\text { importance }\end{array}$ & Triangular fuzzy scale & $\begin{array}{c}\text { Triangular fuzzy } \\
\text { reciprocal scale }\end{array}$ \\
\hline Equal & $(1,1,1)$ & $(1,1,1)$ \\
\hline Weak & $(1 / 2,1,3 / 2)$ & $(2 / 3,1,2)$ \\
\hline Fairly strong & $(3 / 2,2,5 / 2)$ & $(2 / 5,1 / 2,2 / 3)$ \\
\hline Very strong & $(5 / 2,3,7 / 2)$ & $(2 / 7,1 / 3,2 / 5)$ \\
\hline Absolute & $(7 / 2,4,9 / 2)$ & $(2 / 9,1 / 4,2 / 7)$ \\
\hline
\end{tabular}

Table 2

Priority vectors for the decision hierarchy (TF with sub-criteria)

\begin{tabular}{|c|c|c|}
\hline $\begin{array}{c}\text { Level 1 variable } \\
\text { (priority) }\end{array}$ & $\begin{array}{c}\text { Level 2 variables } \\
\text { (priority) }\end{array}$ & Level 3 variables (priority) \\
\hline \multirow{5}{*}{$T$} & $\mathrm{TP}(0.296)$ & $\mathrm{B}_{\mathrm{A}}(0.325), \mathrm{B}_{\mathrm{B}}(0.412), \mathrm{B}_{\mathrm{C}}(0.263)$ \\
\cline { 2 - 3 } $\mathrm{NF}(0.350)$ & $\mathrm{QU}(0.208)$ & $\mathrm{B}_{\mathrm{A}}(0.412), \mathrm{B}_{\mathrm{B}}(0.263), \mathrm{B}_{\mathrm{C}}(0.325)$ \\
\cline { 2 - 3 } & $\mathrm{TD}(0.229)$ & $\mathrm{B}_{\mathrm{A}}(0.000), \mathrm{B}_{\mathrm{B}}(0.958), \mathrm{B}_{\mathrm{C}}(0.042)$ \\
\cline { 2 - 3 } & $\mathrm{WP}(0.005)$ & $\mathrm{B}_{\mathrm{A}}(0.412), \mathrm{B}_{\mathrm{B}}(0.263), \mathrm{B}_{\mathrm{C}}(0.325)$ \\
\cline { 2 - 3 } & $\mathrm{QP}(0.000)$ & $\mathrm{B}_{\mathrm{A}}(0.333), \mathrm{B}_{\mathrm{B}}(0.333), \mathrm{B}_{\mathrm{C}}(0.333)$ \\
\cline { 2 - 3 } & $\mathrm{QC}(0.262)$ & $\mathrm{B}_{\mathrm{A}}(0.457), \mathrm{B}_{\mathrm{B}}(0.457), \mathrm{B}_{\mathrm{C}}(0.086)$ \\
\hline
\end{tabular}

Table 3

Priority vectors for the decision hierarchy (BP with sub-criteria)

\begin{tabular}{|c|c|c|}
\hline $\begin{array}{c}\text { Level 1 variable } \\
\text { (priority) }\end{array}$ & $\begin{array}{c}\text { Level 2 variables } \\
\text { (priority) }\end{array}$ & Level 3 variables (priority) \\
\hline \multirow{4}{*}{$\mathrm{BP}(0.131)$} & $\mathrm{SO}(0.306)$ & $\mathrm{B}_{\mathrm{A}}(0.272), \mathrm{B}_{\mathrm{B}}(0.487), \mathrm{B}_{\mathrm{C}}(0.241)$ \\
\cline { 2 - 3 } & $\mathrm{MP}(0.317)$ & $\mathrm{B}_{\mathrm{A}}(0.497), \mathrm{B}_{\mathrm{B}}(0.158), \mathrm{B}_{\mathrm{C}}(0.345)$ \\
\cline { 2 - 3 } & $\mathrm{RE}(0.367)$ & $\mathrm{B}_{\mathrm{A}}(0.241), \mathrm{B}_{\mathrm{B}}(0.272), \mathrm{B}_{\mathrm{C}}(0.487)$ \\
\cline { 2 - 3 } & $\mathrm{PR}(0.010)$ & $\mathrm{B}_{\mathrm{A}}(0.487), \mathrm{B}_{\mathrm{B}}(0.241), \mathrm{B}_{\mathrm{C}}(0.272)$ \\
\hline
\end{tabular}

Table 4

Priority vectors for the decision hierarchy (FA with sub-criteria)

\begin{tabular}{|c|c|c|}
\hline $\begin{array}{c}\text { Level 1 variable } \\
\text { (priority) }\end{array}$ & $\begin{array}{c}\text { Level 2 variables } \\
\text { (priority) }\end{array}$ & Level 3 variables (priority) \\
\hline \multirow{4}{*}{$\mathrm{FA}(0.299)$} & $\mathrm{OP}(0.349)$ & $\mathrm{B}_{\mathrm{A}}(0.222), \mathrm{B}_{\mathrm{B}}(0.418), \mathrm{B}_{\mathrm{C}}(0.360)$ \\
\cline { 2 - 3 } & $\mathrm{TC}(0.131)$ & $\mathrm{B}_{\mathrm{A}}(0.958), \mathrm{B}_{\mathrm{B}}(0.042), \mathrm{B}_{\mathrm{C}}(0.000)$ \\
\cline { 2 - 3 } & $\mathrm{CF}(0.258)$ & $\mathrm{B}_{\mathrm{A}}(0.228), \mathrm{B}_{\mathrm{B}}(0.614), \mathrm{B}_{\mathrm{C}}(0.165)$ \\
\cline { 2 - 3 } & $\mathrm{PC}(0.262)$ & $\mathrm{B}_{\mathrm{A}}(0.158), \mathrm{B}_{\mathrm{B}}(0.497), \mathrm{B}_{\mathrm{C}}(0.345)$ \\
\hline
\end{tabular}

The results from Tables 2, 3, 4 and 5 shows that the most important criterion is Technical Features, with a total priority value of 0.350 . 
Table 5

Priority vectors for the decision hierarchy (SS with sub-criteria)

\begin{tabular}{|c|c|c|}
\hline $\begin{array}{c}\text { Level 1 variable } \\
\text { (priority) }\end{array}$ & $\begin{array}{c}\text { Level 2 variables } \\
\text { (priority) }\end{array}$ & Level 3 variables (priority) \\
\hline \multirow{4}{*}{$\mathrm{SS}(0.220)$} & $\mathrm{SE}(0.242)$ & $\mathrm{B}_{\mathrm{A}}(0.421), \mathrm{B}_{\mathrm{B}}(0.264), \mathrm{B}_{\mathrm{C}}(0.315)$ \\
\cline { 2 - 3 } & $\mathrm{TA}(0.151)$ & $\mathrm{B}_{\mathrm{A}}(0.239), \mathrm{B}_{\mathrm{B}}(0.342), \mathrm{B}_{\mathrm{C}}(0.419)$ \\
\cline { 2 - 3 } & $\mathrm{TS}(0.217)$ & $\mathrm{B}_{\mathrm{A}}(0.264), \mathrm{B}_{\mathrm{B}}(0.421), \mathrm{B}_{\mathrm{C}}(0.315)$ \\
\cline { 2 - 3 } & $\mathrm{MA}(0.197)$ & $\mathrm{B}_{\mathrm{A}}(0.145), \mathrm{B}_{\mathrm{B}}(0.532), \mathrm{B}_{\mathrm{C}}(0.323)$ \\
\cline { 2 - 3 } & $\mathrm{SP}(0.193)$ & $\mathrm{B}_{\mathrm{A}}(0.421), \mathrm{B}_{\mathrm{B}}(0.315), \mathrm{B}_{\mathrm{C}}(0.264)$ \\
\hline
\end{tabular}

\subsection{Calculation of Criteria and Bidders using the Fuzzy TOPSIS Method}

The application of the fuzzy TOPSIS methodology for bidder selection includes a comparison of bidders, calculation of the distance of each bidder from $D^{*}$ and $D^{-}$and calculation of the similarities to an ideal solution. Using a Linguistic Variables for the Ratings (see Table 6), three decision makers have established the decision matrix by comparing bidders under each of the sub-criteria (see Table 7).

Table 6

Linguistic variables for the ratings

\begin{tabular}{|l|c|c|c|c|c|c|c|}
\hline $\begin{array}{l}\text { Linguistic } \\
\text { variable }\end{array}$ & $\begin{array}{c}\text { Very } \\
\text { poor }\end{array}$ & Poor & $\begin{array}{c}\text { Medium } \\
\text { Poor }\end{array}$ & Fair & $\begin{array}{c}\text { Medium } \\
\text { good }\end{array}$ & Good & $\begin{array}{c}\text { Very } \\
\text { good }\end{array}$ \\
\hline Fuzzy number & $(0,0,2)$ & $(1,2,3)$ & $(2,3.5,4)$ & $(4,5,6)$ & $(5,6.5,8)$ & $(7,8,9)$ & $(8,10,10)$ \\
\hline
\end{tabular}

Table 7

Decision matrix for sub-criteria by three decision makers from public procurement committee

\begin{tabular}{|c|c|c|c|c|c|c|c|c|c|c|c|c|}
\hline & \multicolumn{12}{|c|}{ Sub-criteria } \\
\hline & \multicolumn{3}{|c|}{$\mathrm{TP}$} & \multicolumn{3}{|c|}{$\mathrm{QU}$} & \multicolumn{3}{|c|}{ TD } & \multicolumn{3}{|c|}{ WP } \\
\hline & $\mathbf{B}_{\mathbf{A}}$ & $\mathbf{B}_{B}$ & $\mathbf{B}_{\mathrm{C}}$ & $\mathbf{B}_{\mathrm{A}}$ & $\mathbf{B}_{B}$ & $\mathbf{B}_{\mathbf{C}}$ & $\mathbf{B}_{\mathbf{A}}$ & $\mathbf{B}_{B}$ & $\mathbf{B}_{\mathbf{C}}$ & $\mathbf{B}_{\mathbf{A}}$ & $\mathbf{B}_{\mathbf{B}}$ & $\mathbf{B}_{\mathrm{C}}$ \\
\hline$D M_{l}$ & $\mathrm{G}$ & $\mathrm{VG}$ & $F$ & $\mathrm{VG}$ & $\mathrm{G}$ & $\mathrm{G}$ & $\mathrm{P}$ & $\mathrm{VG}$ & $\mathrm{P}$ & $\mathrm{G}$ & $\mathrm{F}$ & MG \\
\hline $\mathrm{DM}_{2}$ & MG & G & MG & G & MG & G & VP & VG & VP & G & $\mathrm{F}$ & G \\
\hline \multirow[t]{3}{*}{$D M_{3}$} & MG & $\mathrm{VG}$ & $\mathrm{F}$ & $\mathrm{G}$ & $\mathrm{MG}$ & $\mathrm{G}$ & VP & $\mathrm{VG}$ & MP & VG & $\mathrm{F}$ & $\mathrm{MG}$ \\
\hline & \multicolumn{3}{|c|}{$\mathrm{QP}$} & \multicolumn{3}{|c|}{$\mathrm{QC}$} & \multicolumn{3}{|c|}{$\mathrm{SO}$} & \multicolumn{3}{|c|}{ MP } \\
\hline & $\mathbf{B}_{\mathbf{A}}$ & $\mathbf{B}_{B}$ & $\mathbf{B}_{\mathbf{C}}$ & $\mathbf{B}_{\mathrm{A}}$ & $\mathbf{B}_{B}$ & $\mathbf{B}_{\mathrm{C}}$ & $\mathbf{B}_{\mathbf{A}}$ & $\mathbf{B}_{B}$ & $\mathbf{B}_{\mathrm{C}}$ & $\mathbf{B}_{\mathbf{A}}$ & $\mathbf{B}_{\mathbf{B}}$ & $\mathbf{B}_{\mathbf{C}}$ \\
\hline$D M_{l}$ & G & $\mathrm{G}$ & G & G & $\mathrm{G}$ & VP & G & $\mathrm{F}$ & MG & VP & MG & $\mathrm{G}$ \\
\hline$D M_{2}$ & $\mathrm{G}$ & $\mathrm{G}$ & G & $\mathrm{G}$ & $\mathrm{G}$ & $\mathrm{P}$ & $\mathrm{G}$ & $\mathrm{F}$ & MG & VP & $\mathrm{G}$ & $\mathrm{G}$ \\
\hline \multirow[t]{3}{*}{$D M_{3}$} & $\mathrm{G}$ & $G$ & $\mathrm{G}$ & $\mathrm{VG}$ & $\mathrm{VG}$ & $\mathrm{P}$ & $\mathrm{VG}$ & $\mathrm{F}$ & $\mathrm{MG}$ & $\mathrm{VP}$ & $\mathrm{G}$ & $\mathrm{VG}$ \\
\hline & \multicolumn{3}{|c|}{$\mathrm{RE}$} & \multicolumn{3}{|c|}{$\mathrm{PR}$} & \multicolumn{3}{|c|}{$\mathrm{QP}$} & \multicolumn{3}{|c|}{$\mathrm{TC}$} \\
\hline & $\mathbf{B}_{\mathbf{A}}$ & $\mathbf{B}_{\mathrm{B}}$ & $\mathbf{B}_{\mathbf{C}}$ & $\mathbf{B}_{\mathbf{A}}$ & $\mathbf{B}_{\mathrm{B}}$ & $\mathbf{B}_{\mathbf{C}}$ & $\mathbf{B}_{\mathbf{A}}$ & $\mathbf{B}_{\mathbf{B}}$ & $\mathbf{B}_{\mathbf{C}}$ & $\mathbf{B}_{\mathbf{A}}$ & $\mathbf{B}_{\mathbf{B}}$ & $\mathbf{B}_{\mathbf{C}}$ \\
\hline$D M_{I}$ & $\mathrm{~F}$ & $\mathrm{~F}$ & MC & $\mathrm{G}$ & $\mathrm{F}$ & $\mathrm{F}$ & MG & $\mathrm{F}$ & MG & VP & $\mathrm{P}$ & G \\
\hline
\end{tabular}




\begin{tabular}{|c|c|c|c|c|c|c|c|c|c|c|c|c|}
\hline $\mathrm{DM}_{2}$ & $F$ & $\mathrm{~F}$ & VG & $\mathrm{G}$ & $\mathrm{F}$ & $\mathrm{F}$ & $\mathrm{G}$ & $\mathrm{P}$ & $\mathrm{F}$ & VP & $\mathrm{P}$ & $\mathrm{G}$ \\
\hline \multirow[t]{3}{*}{$\mathrm{DM}_{3}$} & MP & $\mathrm{F}$ & MG & $\mathrm{VG}$ & MP & MG & $\mathrm{VG}$ & $\mathrm{VP}$ & MG & VP & VP & $\mathrm{VG}$ \\
\hline & \multicolumn{3}{|c|}{$\mathrm{CF}$} & \multicolumn{3}{|c|}{$\mathrm{PC}$} & \multicolumn{3}{|c|}{ SE } & \multicolumn{3}{|c|}{ TA } \\
\hline & $\mathbf{B}_{\mathrm{A}}$ & $\mathbf{B}_{\mathbf{B}}$ & $\mathbf{B}_{\mathrm{C}}$ & $\mathbf{B}_{\mathrm{A}}$ & $\overline{\mathbf{B}_{\mathrm{B}}}$ & $\mathbf{B}_{\mathrm{C}}$ & $\mathbf{B}_{\mathrm{A}}$ & $\mathbf{B}_{\mathbf{B}}$ & $\mathbf{B}_{\mathbf{C}}$ & $\mathbf{B}_{\mathbf{A}}$ & $\mathbf{B}_{\mathbf{B}}$ & $\mathbf{B}_{\mathrm{C}}$ \\
\hline$D M_{l}$ & $\mathrm{~F}$ & $\mathrm{~F}$ & $\mathrm{G}$ & MP & MG & $\mathrm{F}$ & VG & MG & MG & MG & MG & $\mathrm{G}$ \\
\hline$D M_{2}$ & $F$ & $P$ & $\mathrm{VG}$ & $P$ & $G$ & $F$ & $\mathrm{MG}$ & $\mathrm{F}$ & MG & $\mathrm{F}$ & $\mathrm{MG}$ & $\mathrm{MG}$ \\
\hline \multirow[t]{3}{*}{$D M_{3}$} & $F$ & MP & MG & $\mathrm{F}$ & MG & $\mathrm{F}$ & $\mathrm{MG}$ & $F$ & $F$ & $\mathrm{~F}$ & $\mathrm{~F}$ & $\mathrm{MG}$ \\
\hline & \multicolumn{3}{|c|}{ TS } & \multicolumn{3}{|c|}{ MA } & \multicolumn{3}{|c|}{ SP } & & & \\
\hline & $\mathbf{B}_{\mathrm{A}}$ & $\mathbf{B}_{\mathbf{B}}$ & $\mathbf{B}_{\mathrm{C}}$ & $\mathbf{B}_{\mathrm{A}}$ & $\mathbf{B}_{\mathbf{B}}$ & $\mathbf{B}_{\mathrm{C}}$ & $\mathbf{B}_{\mathrm{A}}$ & $\mathbf{B}_{\mathrm{B}}$ & $\mathbf{B}_{\mathrm{C}}$ & & & \\
\hline$D M_{l}$ & $\mathrm{MG}$ & MG & MG & $F$ & MG & MG & $\mathrm{MG}$ & $\mathrm{MG}$ & $\mathrm{F}$ & & & \\
\hline$D M_{2}$ & $\mathrm{~F}$ & MG & MG & $\mathrm{F}$ & $\mathrm{G}$ & $\mathrm{F}$ & MG & MG & $\mathrm{F}$ & & & \\
\hline$D M_{3}$ & MP & MG & $\mathrm{F}$ & $\mathrm{F}$ & $\mathrm{VG}$ & $G$ & MG & $\mathrm{F}$ & $\mathrm{F}$ & & & \\
\hline
\end{tabular}

Using data from Table 6 and Table 7, the fuzzy matrix is created. Using the subcriterion weights calculated by the fuzzy Extent Analysis Method, the Weighted Normalized Fuzzy Decision Matrix is established with Eq. (5). The results are shown in Table 8.

Table 8

Weighted normalized decision matrix

\begin{tabular}{|c|c|c|c|c|}
\hline & \multicolumn{4}{|c|}{ Sub-criteria } \\
\hline Bidder & TP & QU & TD & WP \\
\hline $\mathrm{B}_{\mathrm{A}}$ & $(0.11,0.16,0.20)$ & $(0.13,0.16,0.18)$ & $(0,0.02,0.06)$ & $(0.09,0.11,0.13)$ \\
\hline $\mathrm{B}_{\mathrm{B}}$ & $(0.16,0.21,0.23)$ & $(0.09,0.13,0.17)$ & $(0.15,0.19,0.19)$ & $(0.05,0.06,0.08)$ \\
\hline \multirow[t]{2}{*}{$\mathrm{B}_{\mathrm{C}}$} & $(0.09,0.12,0.18)$ & $(0.13,0.15,0.17)$ & $(0,0.03,0.07)$ & $(0.06,0.09,0.12)$ \\
\hline & QP & QC & $\mathrm{SO}$ & MP \\
\hline $\mathrm{B}_{\mathrm{A}}$ & $(0.04,0.05,0.06)$ & $(0.14,0.18,0.2)$ & $(0.2,0.25,0.28)$ & $(0,0,0.05)$ \\
\hline $\mathrm{B}_{\mathrm{B}}$ & $(0.04,0.05,0.06)$ & $(0.14,0.18,0.2)$ & $(0.11,0.14,0.17)$ & $(0.12,0.18,0.22)$ \\
\hline \multirow[t]{2}{*}{$\mathrm{B}_{\mathrm{C}}$} & $(0.04,0.05,0.06)$ & $\begin{array}{l}(0,0.03,0.06) \\
\end{array}$ & $(0.14,0.18,0.23)$ & $(0.17,0.21,0.24)$ \\
\hline & $\mathrm{RE}$ & PR & $\mathrm{OP}$ & $\mathrm{TC}$ \\
\hline $\mathrm{B}_{\mathrm{A}}$ & $(0.1,0.11,0.15)$ & $(0.16,0.19,0.22)$ & $(0.17,0.29,0.35)$ & $(0,0,0.03)$ \\
\hline $\mathrm{B}_{\mathrm{B}}$ & $(0.1,0.12,0.15)$ & $(0.09,0.1,0.13)$ & $(0,0.08,0.21)$ & $(0,0.02,0.04)$ \\
\hline \multirow[t]{2}{*}{$\mathrm{B}_{\mathrm{C}}$} & $(0.12,0.19,0.25)$ & $(0.09,0.12,0.18)$ & $(0.14,0.21,0.28)$ & $(0.09,0.11,0.13)$ \\
\hline & $\mathrm{CF}$ & $\mathrm{PC}$ & SE & TA \\
\hline $\mathrm{B}_{\mathrm{A}}$ & $(0.1,0.13,0.15)$ & $(0.03,0.09,0.16)$ & $(0.12,0.19,0.24)$ & $(0.06,0.08,0.12)$ \\
\hline $\mathrm{B}_{\mathrm{B}}$ & $(0.03,0.09,0.15)$ & $(0.1,0.16,0.21)$ & $(0.1,0.13,0.19)$ & $(0.06,0.09,0.12)$ \\
\hline \multirow[t]{2}{*}{$\mathrm{B}_{\mathrm{C}}$} & $(0.13,0.21,0.26)$ & $(0.1,0.13,0,16)$ & $(0.1,0.14,0.19)$ & $(0.07,0.1,0.13)$ \\
\hline & $\mathrm{TS}$ & MA & SP & \\
\hline $\mathrm{B}_{\mathrm{A}}$ & $(0.04,0.11,0.17)$ & $(0.02,0.06,0.12)$ & $(0.1,0.13,0.15)$ & \\
\hline $\mathrm{B}_{\mathrm{B}}$ & $(0.11,0.16,0.19)$ & $(0.1,0.16,0.20)$ & $(0.08,0.12,0.15)$ & \\
\hline $\mathrm{B}_{\mathrm{C}}$ & $(0.09,0.13,0.19)$ & $(0.08,0.13,0.18)$ & $(0.08,0.1,0.12)$ & \\
\hline
\end{tabular}


After that, we define the fuzzy positive-ideal solution $\left(F P I S, A^{*}\right)$ as $\tilde{V}_{i}^{*}=(1,1,1)$ for benefit sub-criterion and $\tilde{V}_{i}^{*}=(0,0,0)$ for the cost subcriterion. Also, we define the fuzzy negative-ideal solution $\left(F N I S, A^{-}\right)$as $\tilde{V}_{i}=(0,0,0)$ for benefit sub-criterion and $\tilde{V}_{i}^{-}=(1,1,1)$ for the cost subcriterion. In this case study, $\mathrm{OP}, \mathrm{TC}$ and $\mathrm{CF}$ are cost sub-criteria, whereas the other sub-criteria are benefiting criteria.

The distance of each bidder from $D^{*}$ and $D^{-}$is calculated by using Eq. (8), (9). The results are shown in Table 9.

Table 9

Rank of bidders

\begin{tabular}{|c|c|c|c|c|}
\hline Bidders & $D_{i}^{*}$ & $D_{i}^{-}$ & $C C_{i}$ & Rank \\
\hline $\mathrm{B}_{\mathrm{A}}$ & 14.483 & 4.653 & 0.243 & 2 \\
\hline $\mathrm{B}_{\mathrm{B}}$ & 14.119 & 4.993 & 0.261 & 1 \\
\hline $\mathrm{B}_{\mathrm{C}}$ & 14.593 & 4.610 & 0.240 & 3 \\
\hline
\end{tabular}

Finally, the similarities to an ideal solution are calculated by using Eq. (10). The results of fuzzy TOPSIS analysis are summarized in Table 9. Based on $C C_{i}$ values, the ranking of the bidders is descending order are $B_{B}(0.261), B_{A}(0.243)$, $B_{C}(0.240)$. The results of the proposed model indicate that $B_{B}$ is the most suitable bidder with a value of 0.261. Analysis of results from Tables 2, 3, 4 and 5 shows that $B_{B}$ has the highest priority value for Technical Features (especially for Technical Performance), Financial Aspect (especially Offered Price), Support and Services (especially Technical Support and Post-Warranty Maintenance). This is very significant because criteria and sub-criteria mentioned above are more important for government contract authority than others.

\section{Conclusions}

A suitable bidder selection procedure within the public procurement process is a strategic decision undertaken by all governments which provide economical, transparent and non-discriminatory work for every government authority. The objective of the government is to carefully assess and select an appropriate bidder able to provide the required product or service, at a specified time and of acceptable price and quality. In this respect, bidder selection in public procurement is a multi-criteria decision problem on account of the fact that the process has many evaluation criteria and alternatives (bidders).

This paper advocates a multi-criteria decision approach in fuzzy environment to bidder selection problem in public procurement in Serbia. In a decision-making 
process concerning public procurement, the use of linguistic variables is highly beneficial when performance values cannot be expressed by means of numerical values. Naturally, bidder evaluation and selection problems within the sphere of public procurement have a determined degree of uncertainty. Therefore, the fuzzy set theory helps convert a decision maker's preferences and experiences into meaningful results by applying linguistic values for measuring each criterion with respect to every bidder. An integrated fuzzy Extent Analysis Method and fuzzy TOPSIS approach for choosing the most suitable bidder for a Data Storage Hardware System has been used for this study. Four essential criteria and nineteen sub-criteria have been analyzed for three bidders. Essential criteria and subcriteria have been determined by means of the existing Public Procurement Law and in cooperation with the public procurement committee. In order to avoid subjectivity in the determination of weights for criteria and sub-criteria, the fuzzy Extent Analysis Method was used to calculate the weights of criteria, while fuzzy TOPSIS was used to rank bidders in public procurement. Actually, the weights obtained from the fuzzy Extent Analysis Method have been included in the decision-making process as they are used in fuzzy TOPSIS calculations. The proposed model yielded very precise results and for that reason, it can be very useful for practical application in all public procurement procedures where we have a combination of quantitative and qualitative evaluation criteria.

Future research in this field could include more methods of multi-criteria analysis like the fuzzy PROMETHEE and fuzzy ELECTRE and furthermore on building a model by combining multiple methods of multi-criteria analysis in order to attain a higher degree of objectivity within public procurement procedures. At the same time, future research in the field of public procurement bidder selection in Serbia could include the design and implementation of an electronic decision support system for a Serbian public procurement web portal which would be based on the integrated model proposed in this paper.

\section{Acknowledgement}

This work was supported by the Administrative Agency for Common Services of Government Authorities which is the government authority for centralized public procurement in Serbia. In addition, the authors are very grateful to the anonymous reviewers for their excellent suggestions and comments that led to an improved version of this paper.

\section{References}

[1] National Assembly of the Republic of Serbia: Public Procurement Law, Official Gazette, No. 124/12, pp. 60-61, 2012

[2] European Commission: A strategy for e-Procurement, MEMO/12/201. http://trade.ec.europa.eu/doclib/docs/2012/march/tradoc_149242.pdf, 2012. Last visited on 25.03.2014 
[3] P. Bajari, G. Lewis: Procurement Contracting with Time Incentives: Theory and Evidence, Quarterly Journal of Economics, Vol. 126, pp. 1173-1211, 2011

[4] M. Falagario, F. Sciancalepore, N. Costantino, R. Pietroforte: Using a DEA-Cross Efficiency Approach in Public Procurement Tenders, European Journal of Operational Research, Vol. 218, No. 2, pp. 523-529, 2012

[5] European Parliament and Council Directive 2004/18: Concerning the Coordination of Procedures for the Award of Public Works, Contracts, Public Supply Contracts and Public Service Contracts, 31 March 2004

[6] F. Sciancalepore, M. Falagario, N. Constantino, R. Pietroforte: MultiCriteria Bid Evaluation of Public Projects. In: Proceedings of the International Conference on 'Management and Innovation for a Sustainable Built Environment', 19-23 June, Amsterdam, Netherlands, 2011; Online on http://misbe2011.fyper.com/proceedings/documents/185.pdf. Last visited on 24.04.2014.

[7] P. L. Lorentziadis: Post-Objective Determination of Weights of the Evaluation Factors in Public Procurement Tenders, European Journal of Operational Research, Vol. 200, pp. 261-267, 2010

[8] B. D. Rouyendegh: A Hybrid Intuitionistic MCDM Model for Supplier Selection. In: Proceedings of the $5^{\text {th }}$ International Conference on 'Agents and Artificial Intelligence" - ICAART 2013, Vol. 2, pp. 519-522, Barcelona, Spain, 2013

[9] V. Bobar: Methodology of Concept Application for Multicriteria Decision Making in the Public e-Procurement Process, Metalurgia International, Vol. 18, No. 4, pp. 128-142, 2013

[10] B. D. Rouyendegh, T. E. Erkan: An Application of the Fuzzy ELECTRE Method for Academic Staff Selection, Human Factors and Ergonomics in Manufacturing \& Service Industries, Vol. 23, No. 2, pp. 107-115, 2013

[11] T. Galli, F. Chiclana, J. Carter, H. Janicke: Modelling Execution Tracing Quality by Means of Type-1 Fuzzy Logic, Journal of Acta Polytechnica Hungarica, Vol. 10, No. 8, pp. 49-67, 2013

[12] L. Bessissa, L. Boukezzi, Dj. Mahi: A Fuzzy Logic Approach to Model and Predi t HV Calbe Insulation Behaviour under Thermal Aging, Journal of Acta Polytechnica Hungarica, Vol. 11, No. 3, pp. 107-123, 2014

[13] L. A. Zadeh.: Fuzzy Sets, Information and Control, Vol. 8, No. 3, pp. 338353,1965

[14] P. Rezaei, K. Rezaei, S. Nazari-Shirkouhi, M. R. J. Tajabadi: Application of Fuzzy Multi-Criteria Decision Making Analysis for Evaluationg and 
Selecting the Best Location for Construction of Underground Dam, Journal of Acta Polytechnica Hungarica, Vol. 10, No. 7, pp. 187-205, 2013

[15] B. D. Rouyendegh: Evaluating Projects Based on Intuitionistic Fuzzy Group Decision Making, Journal of Applied Mathematics, Vol. 2012, pp. $1-16,2012$

[16] B. D. Rouyendegh, S. Erol: The DEA - FUZZY ANP Department Ranking Model Applied in Iran Amirkabir University, Journal of Acta Polytechnica Hungarica, Vol. 7, No. 4, pp. 103-114, 2010

[17] B. D. Rouyendegh, T. E. Erkan: Selection of Academic Staff Using Fuzzy AHP : Pilot Study, Technical Gazette, Vol. 19, No. 4, pp. 923-929, 2013

[18] V. Bobar: Concept of Implementation Public Electronic Procurement in Serbia: Challenges and Risks, InfoM, Vol. 47, pp. 10-15, 2013

[19] N. Costantino, M. Dotoli, M. Falagario, M.P. Fanti: Fuzzy Logic Based Vendor Selection for the Public Procurement Sector: a Case Study; Proceedings of SIGEF 2006, $13^{\text {th }}$ Congress of the International Association for Fuzzy Set Management and Economy, 30 November - 2 December 2006, Hammamet, Tunisia, 2006. Online at http://dee.poliba.it/LabControlli/file_pdf/SIGEF_2006.pdf. Last visited on 24.04.2014.

[20] T. Søreide: Corruption in Public Procurement. Causes, Consequences and Cures, Bergen, Norway: Chr. Michelsen Institute, 2002

[21] D. Y. Chang: Applications of the Extent analysis Method on Fuzzy AHP, European Journal of Operational Research, Vol. 95, pp. 649-655, 1996

[22] G. Büyüközkan, T. Ertay, C. Kahraman, D. Ruan: Determining the Importance Weights for the Design Requirements in the House of Quality using the Fuzzy Analytic Network Approach, International Journal of Intelligent Systems, Vol. 19, No. 5, pp. 443-461, 2004

[23] R. Rostamzadeh, S. Sofian: Prioritizing effective 7Ms to Improve Production Systems Performance using Fuzzy AHP and Fuzzy TOPSIS (case study), Expert Systems with Applications, Vol. 38, No. 5, pp. 51665177,2011

[24] I. Alavi, H. Alinejad-Rokny: Comparison of Fuzzy AHP and Fuzzy TOPSIS Methods for Plant Species Selection (Case study: Reclamation Plan of Sungun Copper Mine; Iran), Australian Journal of Basic \& Applied Sciences, Vol. 5, No.12, 2011

[25] G. Tuzkaya, B. Gülsün, C. Kahraman, D. Özgen: An Integrated Fuzzy Multi-Criteria Decision Making Methodology for Material Handling Equipment Selection Problem and an Application, Expert Systems with Applications, Vol. 3, No. 4, pp. 2853-2863, 2010 
[26] A. Yazdani-Chamzini, A., S. H. Yakhchali: Tunnel Boring Machine (TBM) Selection using Fuzzy Multicriteria Decision Making Methods, Tunnelling and Underground Space Technology, Vol. 30, pp. 194-204, 2012

[27] İ. Ertuğrul, N. Karakaşoğlu: Comparison of Fuzzy AHP and Fuzzy TOPSIS Methods for Facility Location Selection, The International Journal of Advanced Manufacturing Technology, Vol. 39, No. 7-8, pp. 783-795, 2008

[28] N. E. Rezaee, S. H. Zegordi, A. Nazari, M. Sakawa, F. H. Choobar: A Combined Fuzzy Analytic Network Process and Fuzzy-TOPSIS Model for Project Risk Assessment, International Journal of Modeling and Optimization, Vol. 1, No. 4, pp. 275-28, 2011

[29] C. L. Hwang, K. P. Yoon: Multiple Attributes Decision Making Methods and Applications, Berlin: Springer, 1981

[30] I. Ertuğrul: Fuzzy Group Decision Making for the Selection of Facility Location, Group Decision and Negotiation, Vol. 20, No. 6, pp. 725-740, 2011

[31] X. Zhang, L. Gao, D. Barrett, Y. Chen: Evaluating Water Management Practice for Sustainable Mining, Water, Vol. 6, No. 2, pp. 414-433, 2014

[32] C. N. Liao, H. P. Kao: An Integrated Fuzzy TOPSIS and MCGP Approach to Supplier Selection in Supply Chain Management, Expert Systems with Applications, Vol. 38, No. 9, pp. 10803-10811, 2011

[33] C. T. Chen, C. T. Lin, S. F. Huang: A Fuzzy Approach for Supplier Evaluation and Selection in Supply Chain Management, International Journal of Production Economics, Vol. 102, No. 2, pp. 289-301, 2006

[34] M. Dağdeviren, S. Yavuz, N. Kılınç: Weapon Selection using the AHP and TOPSIS Methods under Fuzzy Environment, Expert Systems with Applications, Vol. 36, No. 4, pp. 8143-8151, 2009

[35] O. Kilincci, S. A. Onal: Fuzzy AHP Approach for Supplier Selection in a Washing Machine Company, Expert Systems with Applications, Vol. 38, pp. 9656-9664, 2011 